\title{
RISK FACTORS AND MANAGEMENT OF HEPATITIS B VIRUS REACTIVATION IN PATIENTS WITH HEMATOLOGICAL DISORDERS
}

\author{
Fatih Erkan Akay ${ }^{1}$, Berfin $\operatorname{Tan}^{1}$, Mahmut Alper Güldağ ${ }^{1}$, Hilal Sena Çifcibaşı ${ }^{1}$, Kubilay Elmac1 ${ }^{1}$, Elif Gülsüm Ümit ${ }^{2}$
}

${ }^{1}$ Trakya University School of Medicine, Edirne, TURKEY

${ }^{2}$ Department of Hematology, Trakya University School of Medicine, Edirne, TURKEY

\section{ABSTRACT}

Aims: The aim of this study is to evaluate hepatitis B virus serological status and to categorize the risks of our treatment modalities in patients with both benign and malignant hematological disorders.

Methods: This was a retrospective study of 552 patients who were admitted to the Trakya University Hospital Hematology unit between 01.01.2017 and 31.12.2017. All data regarding the diagnosis, treatment and HBV serological status were collected from patient files. Data were analyzed with IBM SPSS V.20 using descriptive statistical analysis.

Results: Hepatitis B surface antigen was positive in 45 (8.2\%) patients, antibody to the hepatitis B surface antigen was positive in $279(50.5 \%)$ patients and antibody to the hepatitis B core antigen was positive in 247 (44.7\%) patients. According to these results, 32 patients were found to be vaccinated for hepatitis B virus. Reactivation was observed in $4(0.7 \%)$ patients who have been hepatitis B surface antigen positive and have received adequate duration of antiviral prophylaxis with tenofovir. These 4 patients have received monoclonal antibody for immunosuppressive treatment.

Conclusion: To conclude, although the rate of hepatitis B surface antigen reactivation is quite low, as many patients as possible should be vaccinated to reduce the costs of antiviral treatments and monitorization. If there is no time to vaccinate, patients should be categorized according to guidelines by their hepatitis B surface antigen serological status and by the planned immunosuppressive treatments.

Keywords: Hepatitis, hematology, immunotherapy

\section{INTRODUCTION}

The course of hepatitis B virus (HBV) infection depends on the interplay between host's immune status and response and viral replication. In all patients, HBV persists within the body even after sereological recovery. The suppression of immune system with certain treatments brings a risk for reactivation and flare of HBV infection (1). This interplay of HBV and altered immune status of the patient may cause delay in immunosuppresive treatment for the underlying hematological disease or even lead to fulminant hepatic failure and/or death (1).

According to guidelines, before the initiation of immunosuppresive treatment, all patients should be screened for HBV infection (2). Screening test for HBV should include HBV surface antigen (HBsAg) and HBV core antibody (Anti-HBc) which demonstrate the encounter with HBV (3). Depending upon these results, if the patient is HbsAg positive, baseline HBV DNA levels should be measured. In patients who are HBsAg negative but Anti-HBc positive, HBV DNA testing is also recommended depending on the risk of the planned immunosuppressive treatment (4). It is recommended that patients with a positive HBsAg result should also be tested for HBeAg and Anti-HBe. All patients, who are negative for HBV screening and will undergo immunosuppresive treatment, should be vaccinated, preferably before the immunosuppresive treatment (2-5).

Patients who are positive for HBV serology (HbsAg and/or anti-HBc positive) are at risk for HBV reactivation if they receive immunosuppressive treatment. This immunosuppresive treatment may be either for an autoimmune disorder such as immune thrombocytope- 
nia (ITP), autoimmune hemolytic anemia (AHA) or a hematological malignancy like leukemia, lymphoma or myeloma including stem cell transplantation (6).

The aim of our study is to evaluate HBV serological status and to categorize the risks of our treatment modalities in patients with both benign and malignant hematological disorders.

\section{MATERIAL AND METHODS}

This study was approved by Scientific Research Ethics Committee of Trakya University Medical Faculty. Patients who were admitted to Trakya University Hospital Hematology unit between 01.01.2017 and 31.12.2017. All data of 552 patients were screened in a retrospective manner. All patients who are older than 18 years of age were included in the study. All data regarding the diagnosis (bening or malign hematological disorders), treatment (immunomodulatory threapies that the patients received), $\mathrm{HBV}$ status (HBsAg, Anti-HBs, Anti-HBc test results) were collected from the files of patients. With the data obtained, the number of patients, who are vaccined for $\mathrm{HBV}$ and the reactivation rate among patients were planned to be determined, in order to establish the risk of $\mathrm{HBV}$ reactivation in patients recieving immunomodulatory therapies.

Data were analysed with IBM SPSS V.20 using descriptive statistical analysis. Numbers, percentages, arithmetic mean, minimum, maximum were used as descriptive statistics.

\section{RESULTS}

Total number of inpatient admission during a whole year period was 552. Out of all patients, 234 (42.3\%) of them were female, while $318(57.7 \%)$ of them were male. Mean age was 59,12 years and minimum age was 18 years, whereas maximum age was 93 years. Regarding diagnosis of patients, 114 (20.7\%) patients had benign hematological disorders including ITP, AHA and hemostatic disorders; 231 (41.8\%) patients had lymphoma, 97 (17.6\%) had multiple myeloma and 110 (19.9\%) patients had leukemia. 108 (19.6\%) patients were observed to receive non-immunomodulatory treatment while 131 (23.7\%) patients received monoclonal antibodies including rituximab and brentuximab, 253 (45.8\%) patients received conventional chemotherapy, $49(8.9 \%)$ patients received hypomethylating agents and 11 (2\%) patients received targeted therapy containing regimens. Patients who are receiving monoclonal antibodies may also receive conventional treatment. Within combination, 246 (44.6\%) patients received anthracycline category of immunosuppression and 359 (65\%) patients received corticosteroids.

HBsAg was positive in 45 (8.2\%) patients, Anti-HBs in $279(50.5 \%)$ patients and Anti-HBc was positive in 247 (44.7\%) patients. From these results, it was deduced that 32 patients were vaccinated for HBV.

Among the patients, 119 of them were observed to receive antiviral treatment with lamivudine, tenofovir or entecavir. Those patients were observed to receive conventional low dose chemotherapy, hypomethylating agent or short duration of corticosteroids. Of patients receiving corticosteroids, 138 were categorized as long-term and high-dose therapy group and all were on adequate antiviral treatment. Patients who were on low-dose and short-term corticosteroids were either on antiviral treatment or on close monitorization, depending on the patient-physician decision and concerns.

Reactivation was observed in 4 patients $(0.7 \%)$ who have been HBsAg positive and have received adequate duration of antiviral prophylaxis with tenofovir, initiated 2 weeks prior to chemotherapy. All 4 patients had received monoclonal antibody (rituximab) for immunosuppressive treatment.

\section{DISCUSSION}

As high as $70 \%$ of HBsAg positive patients receiving conventional chemotherapy for solid/hematological tumors were reported to develop HBV reactivation. For patients with assumably resolved HBV infection defined as HBsAg negative but AntiHBc positive, reactivation prevalence was reported as $0.3-9 \%$ (1). Any immunosuppresive treatment has a potential to cause $\mathrm{HBV}$ reactivation. However, certain regimens are related with more pronounced risk of activation. The American Gastroenterological Association (AGA) and the American Association for the Study of Liver Diseases (AASLD) have attempted to categorize the level of risk for HBV reactivation among individuals receiving certain immunosuppressive agents $(1,2)$. In the Table 1 , the treatments with rated risks of HBV reactivation are summarized. To be pointed out is that with the development of high technology treatment options, the list of treatments that are associated with HBV reactivation is constantly expanding. Almost all immunosuppressive and immunomodulatory drugs including traditional chemothe- 
Table 1: Immunosuppressive Agents and Risk Classification of HBV Reactivation.

\begin{tabular}{|c|c|c|c|c|}
\hline $\begin{array}{l}\text { Very High Risk ( } 20 \% \\
\text { risk of reactivation) } \\
\text { HBsAg positive pa- } \\
\text { tients }\end{array}$ & $\begin{array}{l}\text { High risk (11- } \\
20 \% \text { risk of reac- } \\
\text { tivation) } \\
\text { HBsAg positive } \\
\text { patients }\end{array}$ & $\begin{array}{l}\text { Moderate Risk } \\
\text { (1-10\% risk of re- } \\
\text { activation) } \\
\text { HBsAg positive } \\
\text { patients }\end{array}$ & $\begin{array}{l}\text { Low Risk }(<1 \% \\
\text { risk of reactiva- } \\
\text { tion) } \\
\text { HBsAg positive } \\
\text { patients }\end{array}$ & Very low risk \\
\hline Rituximab & $\begin{array}{l}\text { High dose corti- } \\
\text { costeroids } \\
(\geq 20 \mathrm{mg} / \text { day, at } \\
\text { least } 4 \text { weeks })\end{array}$ & $\begin{array}{l}\text { Cytotoxic chemo- } \\
\text { therapy without } \\
\text { corticosteroids }\end{array}$ & Methotrexate & \multirow{4}{*}{$\begin{array}{l}\text { HBsAg negative and } \\
\text { anti-HBc positive pa- } \\
\text { tients receiving cyto- } \\
\text { toxic chemotherapy } \\
\text { without glucocorti- } \\
\text { coids, anti-TNF ther- } \\
\text { apy, methotrexate, } \\
\text { or azathioprine. }\end{array}$} \\
\hline Ofatumumab & \multirow[t]{3}{*}{ Alemtuzumab } & $\begin{array}{l}\text { Anti-TNF ther- } \\
\text { apy }\end{array}$ & Azathiopurine & \\
\hline Obinutuzumab & & \multirow{2}{*}{$\begin{array}{l}\text { Anti-rejection } \\
\text { therapy for solid } \\
\text { organ transplan- } \\
\text { tation }\end{array}$} & \multirow{2}{*}{$\begin{array}{l}\text { HBsAg negative } \\
\text { and AntiHBc pos- } \\
\text { itive patients re- } \\
\text { ceiving high dose } \\
\text { ( } \geq 20 \mathrm{mg} / \text { day) cor- } \\
\text { ticosteroids or } \\
\text { alemtuzumab }\end{array}$} & \\
\hline $\begin{array}{l}\text { Hematopoietic stem } \\
\text { cell transplantation }\end{array}$ & & & & \\
\hline
\end{tabular}

rapeutic agents and glucocorticoids, as well as biologic agents (e.g. anti-CD20 and anti-TNF agents), and new classes of drugs, such as targeted treatments like tyrosine kinase inhibitors ans mechanistic target of rapamycin inhibitors, bring the risk of HBV reactivation $(3,4)$.

The major determinant of HBV reactivation in a patient is the HBV serological status. Patients who are HBsAg positive have a greater risk than patients who are HBsAg negative. Among patients who are HBsAg positive, particularly those who are also $\mathrm{HBeAg}$ positive have a much greater risk for $\mathrm{HBV}$ reactivation. $\mathrm{HBsAg}$ negative patients are likely to have a resolved infection. Nevertheless, patients who are HBsAg negative but Anti-HBc positive are at risk for HBV reactivation if immunosuppressive treatment is initiated. Reactivation may occur even in those who are anti-HBs-positive but with a low risk (6).

For patients who are HBsAg negative and receiving rituximab, cyclophosphamide, doxorubicin and prednisone (RCHOP, the gold standart regime for B-cell lymphomas) $\mathrm{HBV}$ reactivation prevalence ranges from $3 \%$ to $41 \%$. The risk for patients who are receiving rituximab for collagen tissue disorders are even lower. This decreased risk may be explained with the underlying immunological condition and concomitant treatments $(7,8)$.

The risk of corticosteroids depends on the dose and duration of treatment. High-dose, prolonged treatments are related with higher risk while it should be stated that low-dose treatment with prolonged use may also bring risk. HBV replication increases in the presence of corticosteroids. This effect may be due to the stimulation of replicative activity with steroids. However, during the replication of HBV, necroinflammation of hepatocytes are suppressed with steroids, and as a result, serum transaminase levels are low. Once the glucocorticods are stopped, viral replication is controlled with active immunity but a necroinflammation develops and transaminase levels increase. The peak increase of transaminases typically occurs 4-6 weeks after withdrawal. Corticosteroids are commonly used within combination regimes and are frequently ignored as a major treatment agent. However, it should be kept in mind that even within combination regimens, the use of corticosterods increases the risk of HBV reactivation (9). In our study, we observed that patients receiving corticosteroids for a short duration (less than 4 weeks) may be just monitorized without antiviral treatment.

Most patients with HBV reactivation are asymptomatic, but in patients with increased transaminase levels, an acute hepatitis infection manifestation may be observed. Jaundice, hepatic failure and even death may be certain.

The diagnosis of HBV reactivation is based on the increase in HBV DNA levels. A detectable HBV DNA level in a corticosteroids for a short duration undetectable HBV DNA; a rise of more than $2 \log 10$ international units/mL compared to baseline or a reverse seroconversion (previously HBsAg negative then HBsAg positive) (1).

Treatment of HBV reactivation is generally supportive measures and antivirals. Tenofovir or entecavir may be used in a treatment-naive patient, decision depending upon the renal functions. These agents should be preferred to lamivudine since lamivudine is related with increased risk of resistance. A patient who previously received lamivudine should be treated with tenofovir due to entecavir monotherapy resistance in lamivudine refractory patients.

The main goal of management in patients with HBV seropositivity should be based on prevention. Patients who will undergo immunosuppressive treatment and are $\mathrm{HBs} \mathrm{Ag}$ positive or $\mathrm{HBsAg}$ negative, anti-HBc positive (regardless of anti-HBs positivity), should be evaluated for antiviral prophylaxis. According to the risk category defined by AASLD and AGA and summarized in Table 1, patients should be evaluated according to HBV serological status and the planned immunosuppressive treatment for the underlying hematological disorder. For patients who have a moderate to very high risk, antiviral therapy should be started concurrently and preferably 
prior to immunosuppression. The duration of antiviral prophylaxis is one year after the last dose of immunosuppression especially, in patients receiving anti-CD20. For patients with low and very low risk, decision to start antiviral therapy may be postponed with close transaminase and HBV DNA monitoring. Lastly, in patients with uncertain risk, the decision to start prophylactic antiviral treatment depends on the physicians' concern (1-5). In our study group we observed a good monitorization in patients with low risk without reactivation.

General approach for the choice of antiviral treatment is tenofovir or entecavir over lamivudine. Lamivudine is recommended only when the first line agents are not available since lamivudine resistance is not rare.

Although the reactivation rate of $\mathrm{HBV}$ was found to be quite low in our study, vaccinating as many patients as possible is advantagous because of its role in reducing costs of antiviral treatments and monitorization. If we do not have time to vaccinate, we shall categorize the patients according to guidelines with their HBV serological status and the planned immunosuppressive treatments.

Ethics Committee Approval: This study was approved by Scientific Researches Committee of Trakya University School of Medicine.

Informed Consent: Written informed consent was obtained from the participants of this study.

Conflict of Interest: The authors declared no conflict of interest.

Author contributions: Concept: FEA, BT, MAG, HSÇ KE, EGÜ. Design: FEA, BT, MAG, HSÇ KE, EGÜ. Supervision: FEA, BT, MAG, HSÇ KE, EGÜ. Resources: FEA, BT, MAG, HSÇ KE, EGÜ. Materials: FEA, BT, MAG, HSÇ KE, EGÜ. Data collection and/or processing: FEA, BT, MAG, HSÇ KE, EGÜ. Analysis and/or Interpretation: FEA, BT, MAG, HSÇ, KE, EGÜ. Literature Search: MAG, HSÇ, KE, EGÜ. Writing Manuscript: FEA, BT, MAG, HSÇ, KE, EGÜ. Critical Review: FEA, BT, MAG, HSÇ KE, EGÜ.

Financial disclosure: The authors declared that this study received no financial support.

Editor-in-chief's Note: Five of the authors of this article, Fatih Erkan Akay, Berfin Tan, Mahmut Alper Güldağ, Sena Çiftçibaşı and Kubilay Elmacı are members of the editorial board of Turkish Medical Student Journal. However, they did not take place in any stage on the editorial decision of the manuscript. The editors who evaluated this manuscript are from another institutions.

\section{REFERENCES}

1. Reddy KR, Beavers KL, Hammond SP et al. American Gastroenterological Association Institute guideline on the prevention and treatment of hepatitis B virus reactivation during immunosuppressive drug therapy. Gastroenterology 2015;148:215-9.

2. European Association For The Study Of The Liver. EASL clinical practice guidelines: management of chronic hepatitis B virus infection. J Hepatol 2017;67(2):37098.

3. Di Bisceglie AM, Lok AS, Martin P et al. Recent US Food and Drug Administration warnings on hepatitis $B$ reactivation with immune-suppressing and anticancer drugs: just the tip of the iceberg? Hepatology 2015; 61:703-11.

4. Hwang JP, Somerfield MR, Alston-Johnson DE et al. hepatitis $B$ virus screening for patients with cancer before therapy: American Society of Clinical Oncology provisional clinical opinion update. J Clin Oncol 2015; 33:2212-20.

5. Perrillo RP, Gish R, Falck-Ytter YT. American Gastroenterological Association Institute technical review on prevention and treatment of hepatitis B virus reactivation during immunosuppressive drug therapy. Gastroenterology $2015 ; 148: 221-4$.

6. Perrillo RP, Martin P, Lok AS. Preventing hepatitis $B$ reactivation due to immunosuppressive drug treatments. JAMA 2015;313:1617-8.

7. Mozessohn L, Chan KK, Feld JJ et al. Hepatitis B reactivation in $\mathrm{HBsAg}$-negative/ $\mathrm{HBcAb}$-positive patients receiving rituximab for lymphoma: a meta-analysis. J Viral Hepat 2015;22:842-9.

8. Huang H, Li X, Zhu J et al. Entecavir vs lamivudine for prevention of hepatitis $\mathrm{B}$ virus reactivation among patients with untreated diffuse large B-cell lymphoma receiving R-CHOP chemotherapy: a randomized clinical trial. JAMA 2014;312:2521-30.

9. Hui CK, Cheung WW, Au WY et al. Hepatitis B reactivation after withdrawal of pre-emptive lamivudine in patients with haematological malignancy on completion of cytotoxic chemotherapy. Gut 2005;54:1597-603. 